\title{
Body Mass Index and Cancer Risk: The Evidence for Causal Association
}

\author{
Andrew G. Renehan ${ }^{*}, 1$, Matthias Egger ${ }^{2}$ and Marcel Zwahlen ${ }^{2}$ \\ ${ }^{I}$ Department of Surgery, School of Cancer, Enabling Sciences and Technology, University of Manchester, UK \\ ${ }^{2}$ Institute of Social and Preventive Medicine (ISPM), University of Bern, Switzerland
}

\begin{abstract}
Increased body mass index (BMI), as an approximation of body adiposity, is a risk factor for developing several adult malignancies. To quantify these risks, we reported a comprehensive systematic review (Lancet 2008; 371: 569-78) of prospective observational studies determining associations between BMI and risk of incident cancer for 20 cancer types. We demonstrated that associations are: (i) sex-specific; (ii) exist for a wider range of malignancies than previously thought; and (iii) are broadly consistent across geographic populations. In the present paper, we tested these data against the Bradford-Hill criteria of causal association, and argue that the available data support strength of association, consistency, specificity, temporality, biological gradient, plausibility, coherence and probably analogy. However, the experimental evidence supporting reversibility is currently lacking, though indirect evidence from longitudinal data in cohort studies and long-term follow-up post-bariatric surgery is emerging. We additionally assessed these data against appropriate adjustment for available confounding factors; measurement error and study design; and residual confounding; and found lack of alternative explanations. We conclude that there is considerable evidence to support a causal association between BMI and risk for many cancer types, but in order to establish the role of weight control in cancer prevention, there is a need to develop trial frameworks in which to better test reversibility.
\end{abstract}

Keywords: Body mass index, obesity, cancer risk, causal association.

\section{INTRODUCTION}

Increased body mass index (BMI), as an approximation of body adiposity, is an established risk factor for developing adult malignancies. In 2002, the International Agency for Research into Cancer (IACR) [1] concluded, from a semiquantitative review of the literature, that excess bodyweight is associated with increased risk of developing cancers of the postmenopausal breast, colorectum, endometrium, kidney, and oesophageal adenocarcinoma. In 2007, the World Cancer Research Fund (WRCF) [2] used a more standardised approach to review the literature and reported that the evidence that body fatness is associated with increased risk of oesophageal adenocarcinoma, and with cancers of the pancreas, colorectum, postmenopausal breast, endometrium, and kidney is convincing, and that a probably association exists between body fatness and risk of gallbladder cancer.

Extending the above evidence, we recently reported a systematic review [3] and standardised meta-analysis of prospective observational studies (221 datasets including 281,137 incident cases) quantifying associations with a 5 $\mathrm{kg} / \mathrm{m}^{2} \mathrm{BMI}$ increase and risk of incident cancer for 20 cancer types. We demonstrated that associations are: (i) sexspecific; (ii) exist for a wider range of malignancies than previously thought; and (iii) are broadly consistent across geographic populations.

*Address correspondence to this author at the Department of Surgery, University of Manchester, Manchester Academic Health Science Centre, The Christie NHS Foundation Trust, Wilmslow Road, Manchester M20 4BX United Kingdom; Tel: +44 161446 3157; Fax: +44 161446 3365; E-mail: arenehan@picr.man.ac.uk
While the above syntheses demonstrate associations, a key question (not least for the development of cancer prevention strategies) is whether these are causally related. The aim of this review was to test the data from our systematic review against the nine Bradford-Hill criteria [4, 5] for judging causal association. Furthermore, investigators have argued that additional criteria for assessing causality should include adjustment for available confounding factors; evaluation of measurement error and study design; and assessment of residual confounding [6] - and these too were evaluated.

\section{CAUSAL ASSOCIATION - BRADFORD-HILL CITE- RIA}

\section{Strength of Association}

\section{A Strong Association is More Likely to have a Causal Component than is a Modest Association}

Hill [4] illustrated this point with the high risk ratios for the association between exposure levels of smoking and incidence of lung cancer. However, he equally demonstrated with two counter-examples that the absence of a strong association does not rule out a causal effect and recognised that the impression of strength of association depended on the index used for the magnitude of association. For our systematic review, the index was BMI as an approximation of body adiposity. As BMI represents a spectrum of exposures (rather than a binary exposure), the size of the risk estimate is expressed relative to a given change in BMI. Accordingly, we chose $5 \mathrm{~kg} / \mathrm{m}^{2}$ increments (Table 1), such that increases in BMI of 5,10 and $15 \mathrm{~kg} / \mathrm{m}^{2}$ are broadly equivalent to World Health Organisation [7] categories - 
Table 1. Summary Estimates for Associations between BMI (per $5 \mathrm{~kg} / \mathrm{m}^{2}$ Increment Increase)

\begin{tabular}{|c|c|c|c|c|c|c|c|c|c|c|}
\hline & \multicolumn{5}{|c|}{ MEN } & \multicolumn{5}{|c|}{ WOMEN } \\
\hline & $\begin{array}{l}\text { No. of } \\
\text { Studies }\end{array}$ & $\begin{array}{l}\text { No. of } \\
\text { Cases }\end{array}$ & RR (95\% CIs) & $\mathbf{P}$ & $\mathbf{I}^{2}$ & $\begin{array}{l}\text { No. of } \\
\text { Studies }\end{array}$ & $\begin{array}{l}\text { No. of } \\
\text { Cases }\end{array}$ & RR (95\% CIs) & $\mathbf{P}$ & $\mathbf{I}^{2}$ \\
\hline \multicolumn{11}{|l|}{ Colorectal cancer } \\
\hline Colon & 22 & 22,440 & $1.24(1.20,1.28)$ & $<0.0001$ & $21 \%$ & 19 & 20,975 & $1.09(1.05,1.13)$ & $<0.0001$ & $39 \%$ \\
\hline Rectum & 18 & 14,894 & $1.09(1.06,1.12)$ & $<0.0001$ & $3 \%$ & 14 & 9052 & $1.02(1.00,1.05)$ & 0.26 & $0 \%$ \\
\hline \multicolumn{11}{|l|}{ Gastro-oesophageal cancers } \\
\hline Gastric & 8 & 817 & $0.97(0.88,1.06)$ & 0.49 & $35 \%$ & 5 & 325 & $1.04(0.90,1.20)$ & 0.56 & $4 \%$ \\
\hline $\begin{array}{r}\text { Oesophageal } \\
\text { adenocarcinoma }\end{array}$ & 5 & 1315 & $1.52(1.33,1.74)$ & $<0.0001$ & $24 \%$ & 3 & 735 & $1.51(1.31,1.74)$ & $<0.0001$ & $0 \%$ \\
\hline $\begin{array}{l}\text { Oesophageal squamous cell } \\
\text { carcinoma }\end{array}$ & 3 & 6201 & $0.71(0.60,0.85)$ & $<0.0001$ & $49 \%$ & 2 & 1114 & $0.57(0.47,0.69)$ & $<0.0001$ & $60 \%$ \\
\hline \multicolumn{11}{|l|}{ Hepatobiliary cancers } \\
\hline Gallbladder & 4 & 928 & $1.09(0.99,1.21)$ & 0.12 & $0 \%$ & 2 & 1111 & $1.59(1.02,2.47)$ & 0.04 & $67 \%$ \\
\hline Liver & 4 & 2039 & $1.24(0.95,1.62)$ & 0.12 & $83 \%$ & 1 & 31 & $1.07(0.55,2.08)$ & NA & NA \\
\hline Leukaemia & 7 & 3371 & $1.08(1.02,1.14)$ & 0.009 & $0 \%$ & 7 & 5317 & $1.17(1.04,1.32)$ & 0.01 & $80 \%$ \\
\hline Lung cancer & 11 & 7426 & $0.76(0.70,0.83)$ & $<0.0001$ & $63 \%$ & 6 & 4273 & $0.80(0.66,0.97)$ & 0.03 & $84 \%$ \\
\hline Malignant melanoma & 6 & 3492 & $1.17(1.05,1.30)$ & 0.004 & $44 \%$ & 5 & 4786 & $0.96(0.92,1.01)$ & 0.05 & $0 \%$ \\
\hline Multiple myeloma & 7 & 4273 & $1.11(1.05,1.18)$ & $<0.0001$ & $7 \%$ & 6 & 3664 & $1.11(1.07,1.15)$ & $<0.0001$ & $0 \%$ \\
\hline Non-Hodgkin's lymphoma & 6 & 7041 & $1.06(1.03,1.09)$ & $<0.0001$ & $0 \%$ & 7 & 6248 & $1.07(1.00,1.14)$ & 0.05 & $47 \%$ \\
\hline Pancreatic cancer & 12 & 2390 & $1.07(0.93,1.23)$ & 0.33 & $70 \%$ & 11 & 2053 & $1.12(1.02,1.22)$ & 0.01 & $43 \%$ \\
\hline Renal cancer & 11 & 6073 & $1.24(1.15,1.34)$ & $<0.0001$ & $37 \%$ & 12 & 4614 & $1.34(1.25,1.43)$ & $<0.0001$ & $45 \%$ \\
\hline Thyroid cancer & 4 & 1212 & $1.33(1.04,1.70)$ & 0.02 & $77 \%$ & 3 & 2375 & $1.14(1.06,1.23)$ & 0.001 & $5 \%$ \\
\hline Prostate cancer & 27 & 70,421 & $1.03(1.00,1.07)$ & 0.11 & $73 \%$ & & & & & \\
\hline \multicolumn{11}{|l|}{ Breast cancer } \\
\hline Pre-menopausal & & & & & & 20 & 7930 & $0.92(0.88,0.97)$ & 0.001 & $39 \%$ \\
\hline Post-menopausal & & & & & & 31 & 23,909 & $1.12(1.08,1.16)$ & $<0.0001$ & $64 \%$ \\
\hline Endometrial cancer & & & & & & 19 & 17,084 & $1.59(1.50,1.68)$ & $<0.0001$ & $77 \%$ \\
\hline Ovarian & & & & & & 13 & 12,208 & $1.03(0.99,1.08)$ & 0.30 & $55 \%$ \\
\hline
\end{tabular}

NA: not applicable.

overweight, class I obese, and class II obese. From our metaanalysis, the point estimates for the top four ranking malignancies in men per increases in BMI of 5, 10 and 15 $\mathrm{kg} / \mathrm{m}^{2}$ are: $1.52,2.04,2.56$ for oesophageal adenocarcinoma; $1.33,1.66,1.99$ for thyroid cancer; and $1.24,1.48,1.72$ for colon and renal cancers, respectively. For women, the point estimates for the top four ranking malignancies per increases in BMI of 5, 10 and $15 \mathrm{~kg} / \mathrm{m}^{2}$ are: $1.22,1.73,2.99$ for endometrial cancer (see section on "biological gradient" below); 1.59, 2.18, 2.77 for gallbladder cancer; 1.51, 2.02, 2.53 for oesophageal adenocarcinoma; and 1.34, 1.68, 2.02 for renal cancer, respectively.
The strength of evidence of an association (based mainly on the number of studies and cases) may also be relevant. For malignancies with strong associations, estimates were based on at least one thousand cases; the exception was oesophageal adenocarcinoma in women $(\mathrm{n}=735)$. Associations for rectal cancer in men and endometrial cancer were based on greater than ten thousand cases each; associations for colon cancer (both genders) and postmenopausal breast cancer were based on twenty thousand cases each.

In summary, the associations between increased BMI and incident cancer risk are strong for several cancers based on size of estimate and number of observed cases. 


\section{Consistency}

\section{A Relationship is Observed Repeatedly}

For Hill [4], the repeated observation of an association included "different persons, places, circumstances and time".
Because our meta-analysis [3] used a standardised approach to the dose-response analysis - expressed per $5 \mathrm{~kg} / \mathrm{m}^{2}$ - we circumvented different BMI category cut-off points for AsiaPacific populations [8], and showed for the first time that positive associations between BMI and risk of several cancer

A

Renal Cancer Men

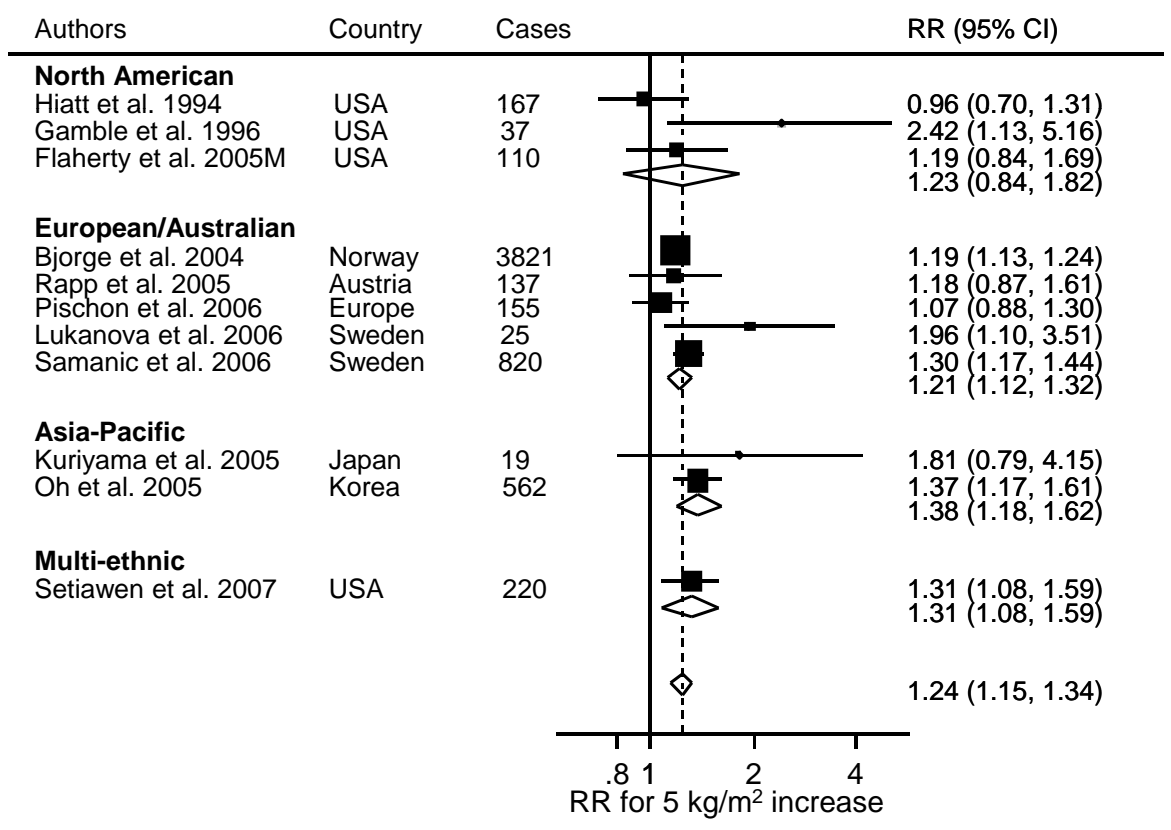

B

Pre-menopausal Breast Cancer

\begin{tabular}{|c|c|c|c|}
\hline Authors & Country & Cases & $\mathrm{RR}(95 \% \mathrm{Cl})$ \\
\hline $\begin{array}{l}\text { North American } \\
\text { Yong et al. } 1996 \\
\text { Huang et al. } 1997 \\
\text { Sonnnenschein et al. } 1999 \\
\text { Michels et al. } 2006 \\
\text { Silvera et al. } 2006\end{array}$ & $\begin{array}{l}\text { USA } \\
\text { USA } \\
\text { USA } \\
\text { USA } \\
\text { Canada }\end{array}$ & $\begin{array}{l}226 \\
1000 \\
109 \\
1398 \\
818\end{array}$ & $\begin{array}{l}0.94(0.78,1.14) \\
0.84(0.77,0.92) \\
0.89(0.67,1.18) \\
0.91(0.86,0.97) \\
1.04 \quad(0.90,1.19) \\
0.91(0.85,0.98)\end{array}$ \\
\hline $\begin{array}{l}\text { European/Australian } \\
\text { Vatten \& Kvinnsland } 1992 \\
\text { DeStavalo et al.1993 } \\
\text { Kaaks et al. } 1998 \\
\text { Manjer et al. } 2001 \\
\text { Lahmann et al. } 2004 \\
\text { Weiderpass et al.2004 } \\
\text { Lukanova et al. } 2006 \\
\text { Tehard et al. } 2006 \\
\text { Reeves et al. } 2007\end{array}$ & $\begin{array}{l}\text { Norway } \\
\text { UK } \\
\text { NL } \\
\text { Sweden } \\
\text { Europe } \\
\text { Sweden/Norway } \\
\text { Sweden } \\
\text { Erance } \\
\text { UK }\end{array}$ & $\begin{array}{ll}164 & \\
73 & \\
147 & \\
112 & \\
474 & \\
733 \\
92 \\
275 \\
1179\end{array}$ & $\begin{array}{l}0.82(0.72,0.94) \\
1.03 \\
0.97(0.73,1.45) \\
1.03(0.76,1.25) \\
0.90(0.82,1.00) \\
0.81(0.67,0.97) \\
0.65(0.44,0.95) \\
0.78(0.56,1.08) \\
0.93(0.86,1.00) \\
0.89(0.84,0.94)\end{array}$ \\
\hline $\begin{array}{l}\text { Asia-Pacific } \\
\text { Galanis et al. } 1998 \\
\text { Kuriyama et al. } 2005 \\
\text { Li et al. } 2006 \\
\text { Wu et al. } 2006 \\
\text { Iwasaki et al. } 2007\end{array}$ & $\begin{array}{l}\text { Hawaii } \\
\text { Japan } \\
\text { China } \\
\text { Taiwan } \\
\text { Japan }\end{array}$ & $\begin{array}{l}86 \\
33 \\
221 \\
64 \\
201\end{array}$ & $\begin{array}{l}1.24(0.89,1.72) \\
0.86(0.42,1.78) \\
1.03(0.81,1.33) \\
1.33(0.90,1.96) \\
1.20(0.97,1.49) \\
1.16(1.01,1.32)\end{array}$ \\
\hline $\begin{array}{l}\text { Black American } \\
\text { Palmer et al. } 2007\end{array}$ & US Black & 495 & $\begin{array}{l}0.91(0.84,0.99) \\
0.91(0.84,0.99) \\
0.92(0.88,0.97)\end{array}$ \\
\hline & & 81 & $T$ \\
\hline & & & \\
\hline
\end{tabular}

Fig. (1). (A) Forest plot of the associations between $5 \mathrm{~kg} / \mathrm{m}^{2}$ BMI increase and renal cancer risk in men, stratified by main geographic populations. (B) Forest plot of the associations between $5 \mathrm{~kg} / \mathrm{m}^{2}$ BMI increase and pre-menopausal breast cancer, stratified by main geographic populations. 
types is broadly consistent across geographic populations. An illustration of this is shown for renal cancer in men in Fig. (1A). However, there were examples of different patterns of associations, notably illustrated by premenopausal breast cancer risk - this association is inverse for North American, and European and Australian populations, but elevated for Asia-Pacific populations (Fig. 1B). A possible explanation may be as follows: the risks of cardiovascular disease and type 2 diabetes are elevated at lower BMI values among Asian populations compared with populations of American and European origin [8] due to greater percentage body fat per BMI category. In a similar manner, the increased risk of premenopausal breast cancer among women might be explained by their greater percentage of body fat per BMI category, and by extrapolation, BMI may be a poor surrogate of adiposity in the younger woman of European descent (see also later under Coherence). Additionally, there may be differences in the patterns and extents of BMI-cancer associations among North American Blacks compared with Whites as reported in a large study of US Veterans and using obesity on hospital discharge as the determinant of exposure [9]. However, risk estimates for pre-menopausal breast cancer in one all Black American study [10] are similar to those for studies from Caucasian populations. These inconsistencies need further substantiation.

Consistency across studies can be assessed statistically using a test of heterogeneity, the $\mathrm{I}^{2}$ statistics [11], as a measure of the proportion of total variation in estimates. The $\mathrm{I}^{2}$ values of $25 \%, 50 \%$ and $75 \%$ correspond to cut-off points for low, moderate and high degrees of heterogeneity. Between-study heterogeneity was high for thyroid and liver cancer in men, and endometrial and lung cancers and leukaemia in women; for the remainder, between-study heterogeneity was moderate or low indicating consistency of associations.

In summary, the associations between increased BMI and incident cancer risk are broadly consistent across geographic populations and generally demonstrate low levels of between-study heterogeneity.

\section{Specificity}

\section{A Factor Influences a Particular Outcome or Population}

For Hill [4], if one observed an association that was specific for an outcome or group of individuals, this was a strong argument for a causal effect. Of course, in the example of BMI and cancer risk, the risk exposure (i.e. adiposity) may cause several other diseases (for example, type 2 diabetes), and in turn, cancers associated with BMI may have multiple risk factors. Despite this, there was clear evidence from our meta-analysis [3] that the associations between BMI and a given cancer type differed in a sexspecific manner. This was best illustrated for colon, rectal and renal cancers (Table 2). Thus, the associations between BMI and colon and rectal cancers were stronger in men compared with women; but the reverse was observed for renal cancer. Furthermore, for large bowel, associations were stronger for colon compared with rectum within the same sex. Other examples of specificity included: (i) associations for pre-menopausal breast cancer differed for Asia-Pacific populations compared with Caucasian North American and European/Australian populations; (ii) associations were in the main for non-smoking related cancers; and (iii) strengths of associations differed across cancer types.

\section{Temporality}

\section{The Factor Must Precede the Outcome it is Assumed to Affect}

Hill [4] introduced this reflection with the proverb "which is the cart and which is the horse?". According to Hill, temporal direction might be difficult to establish if a disease developed slowly as is the case for most adult cancers. It is therefore important to have several years duration from BMI determination to cancer diagnosis. To assess this in our systematic review [3], we plotted the mean follow-up for each study categorised per cancer site - these are shown in Fig. (2). The analysis covered approximately 133 million person-years of follow-up with geometric mean follow-up periods varying from 8.8 years (breast cancer) to 14.4 years (multiple myeloma). The lower confidence interval was greater than 7 years for all sites. These durations are considerably longer than, for instance, meta-analyses of the association between BMI and cardiovascular diseases $[12,13]$ and diabetes risk [14]. These time periods from baseline determination of BMI to cancer diagnosis argue against confounding such as survival biases and reversal causality i.e. the presence of cancer altering body weight. The latter may have been a concern if we had included conventional case-control studies in our review.

Table 2. Comparisons of Risk Ratios in Men and Women for Colon, Rectal and Renal Cancers*

\begin{tabular}{|c|c|c|c|}
\hline \multirow{2}{*}{} & Ren & Women & \multirow{2}{*}{ P value $\uparrow$} \\
\cline { 2 - 4 } & $1.24(1.18-1.31)$ & $1.08(1.02-1.34)$ & $<0.0001$ \\
\hline \hline Colon cancer & $1.08(1.05-1.11)$ & $1.01(0.98-1.04)$ & 0.003 \\
\hline Rectal cancer & $1.18(1.08-1.29)$ & $1.35(1.29-1.42)$ & 0.004 \\
\hline Renal cancer & Mer $\mathbf{5} \mathbf{~ k g} / \mathbf{m}^{2}$ increase & \\
\hline
\end{tabular}

*Risk ratios shown are those where studies reported estimates for both sexes.

$\dagger$ Meta-regression analysis with multivariate models including the method of BMI determination (measured or self-reported); extent of cancer-site specific risk factor adjustment; and geographic population.

CI: confidence interval. 


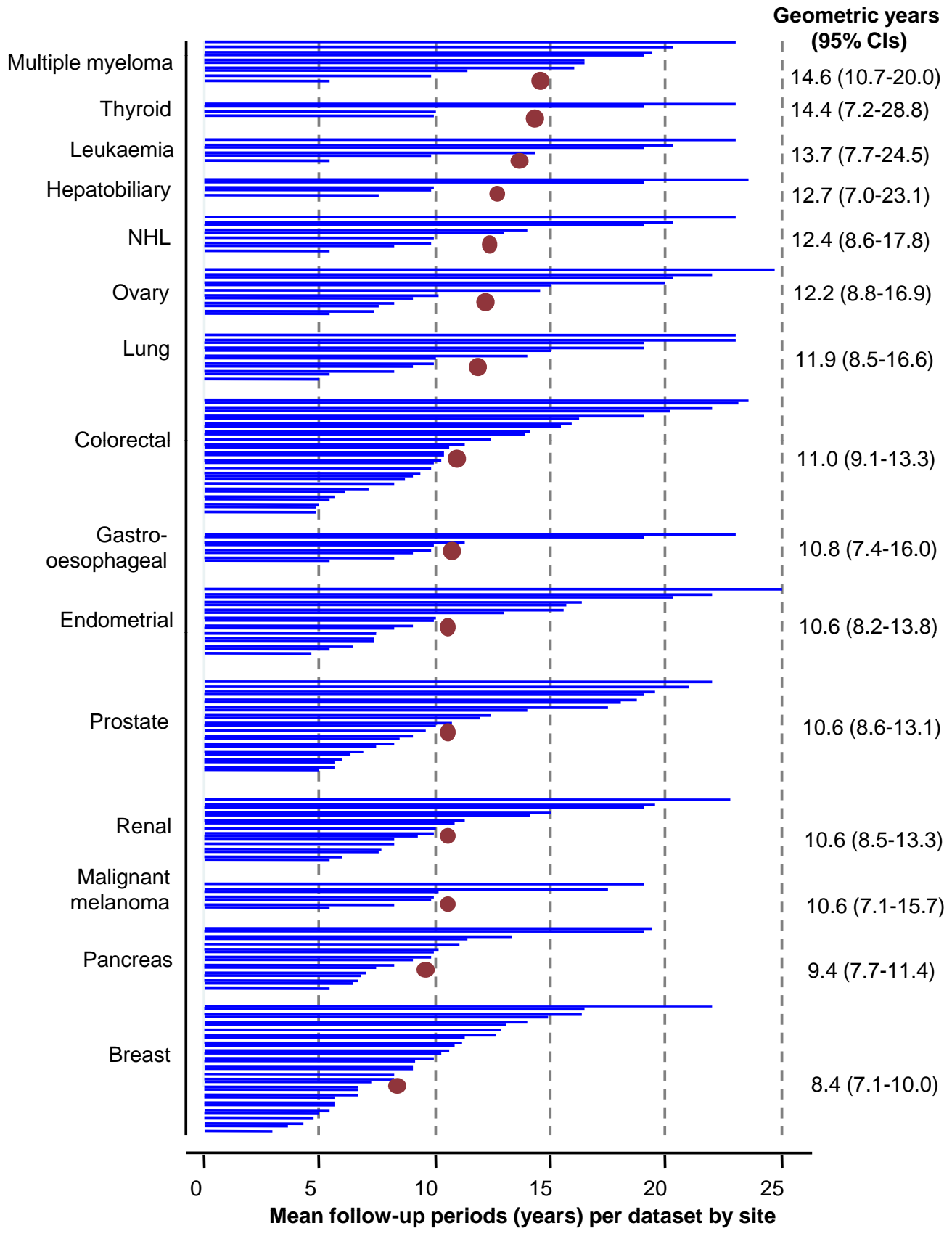

Fig. (2). Follow-up periods in the systematic review. The horizontal blue lines represent geometric mean per dataset. Data were available for 174 (out of 185) datasets. The geometric means per site are shown by the purple solid circle. The values for medians were similar.

\section{Biological Gradient}

The Outcome Increases Monotonically with Increasing dose of Exposure or According to a Function Predicted by a Substantive Theory

Hill [4] favoured linear relationships between exposure and outcome, pointing out that if the shape of the doseresponse relationship were a more complex, non-monotonic, function, this would require a complex substantive explanation. For example, J-shaped dose-response curves might be caused by the respective exposure levels while others might be due to confounding. Thus, for example, the relationship between BMI and all-cause mortality is J-shaped [15, 16], but it has recently become clear through individual-patient based analysis of 57 prospective cohorts that the apparent increase in mortality at low BMI levels reflects mainly smoking-related illnesses [17].

To address this in our systematic review [3], we assessed the assumption of linearity visually by plotting the $\ln [\mathrm{RR}]$ for each study BMI category against BMI. The plots suggested linear associations for all cancer types. The exception was endometrial cancer which was handled as two "slopes" pivoted at BMI $=27 \mathrm{~kg} / \mathrm{m}^{2}$ (Fig. 3) - this inflection was determined using a goodness-of-fit approach in a generalised least squares for trends (GLST) estimation model as described by Orsini and colleagues [18]. 


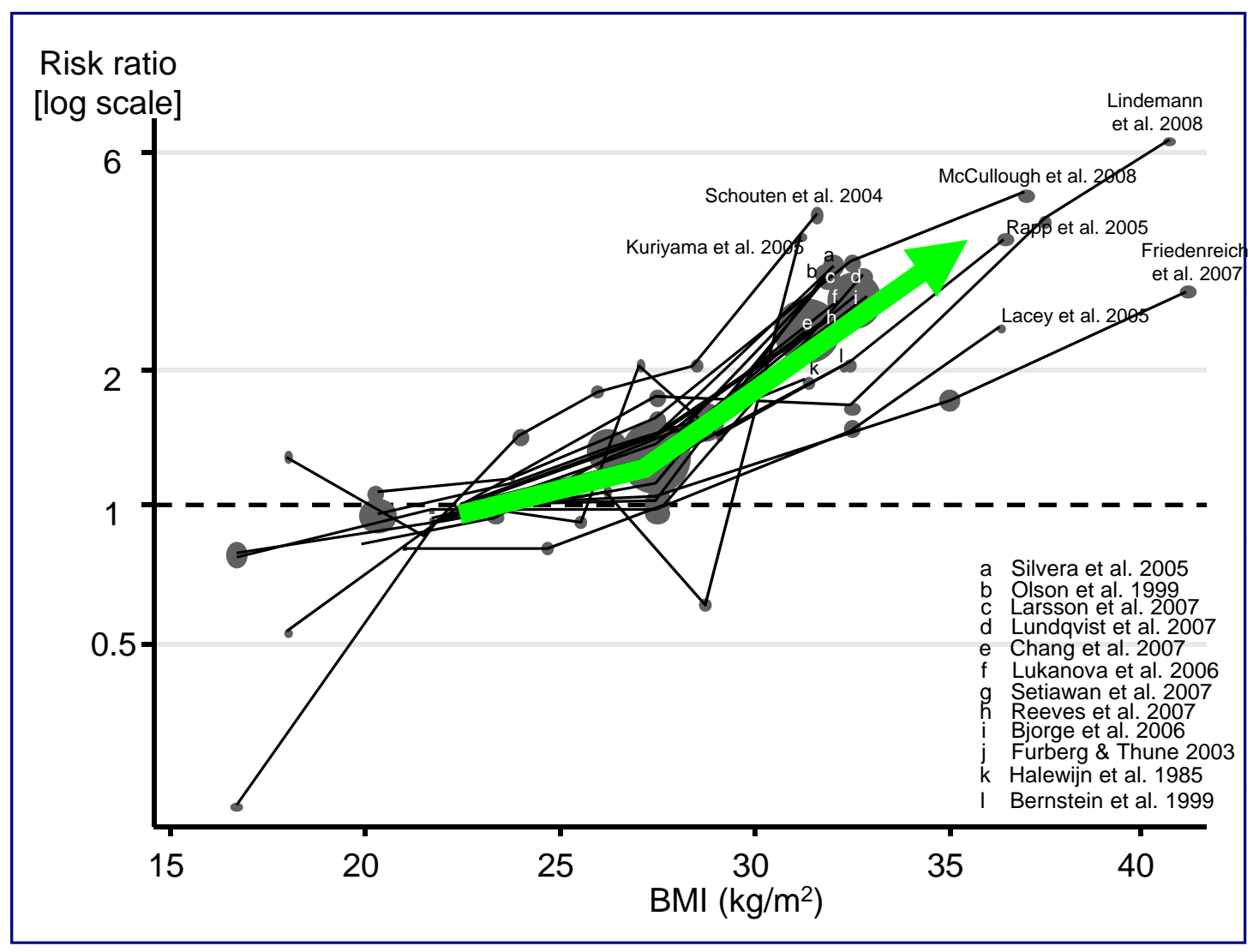

Fig. (3). Relationship of BMI and endometrial cancer risk. The graph shows representation of each study plot of risk versus BMI. Each study is a line; the circles represent the risk at the midpoint of each BMI category per study; the size of the circle is proportional to the sample size per BMI category. The first author of each study is listed against each plot. The BMI-cancer risk association for endometrial cancer was modelled as two "slopes" pivoted at BMI $=27 \mathrm{~kg} / \mathrm{m}^{2}$ (green solid line). This inflection was determined using a goodness-of-fit approach in a generalised least squares for trends (GLST) model.

\section{Plausibility}

\section{The Observed Association can be Plausibly Explained by Substantive (e.g. Biological) Explanations}

The mechanisms linking excess weight and cancer risk are not fully understood (Table 3), though three hormonal systems - insulin and insulin-like growth factor (IGF) axis, sex steroids, and adipokines - are the most studied candidates [19]. While all three systems are interlinked through insulin, their roles may vary between cancer sites. The insulin-IGF hypothesis postulates that chronic hyperinsulinaemia decreases concentrations of IGF binding proteins -1 and -2 , leading to increased bio-available or free IGF-I with concomitant changes in the cellular environment (IGF-I increases mitosis, is anti-apoptotic, pro-angiogenic, and increases cell motility) favouring tumour formation [20]. Circulating total IGF-I, a major determinant of free IGF-I concentrations, is also consistently associated with increased risk of prostate, colorectal and pre-menopausal breast cancers [21], and in some studies of post-menopausal breast cancer [22, 23]. Mean circulating concentrations of total IGF-I are higher in men than women [24], which may part explain some observed differences, for instance, in colorectal cancer risk are greater in men compared with women. However, the insulin-IGF hypothesis has two fundamental inconsistencies - first, levels of total IGF-I increase linearly with increasingly BMI but only to a pivotal point around 27 $\mathrm{kg} / \mathrm{m}^{2}$, thereafter declining with increasing weight [20]; second, in overweight individuals who intentionally lose weight, total IGF-I concentrations tend to increase [25].

For post-menopausal breast cancer, the increase in risk might be explained by the higher rates of conversion of androgenic precursors to oestradiol through increased aromatase enzyme activity in adipose tissue. In endometrial cancer, there may be more than one system involved: increased oestradiol levels not only increase endometrial cell proliferation and inhibit apoptosis, but might also stimulate the local synthesis of IGF-I in endometrial tissue [26]. Furthermore, chronic hyperinsulinaemia may promote tumorigenesis in oestrogen-sensitive tissues by reducing blood concentrations of sex hormone binding globulin, which in turn, increases bio-available oestrogen [26]. Adiposity is inversely related to testosterone concentrations in men [27], but positively related in women [28], which may be relevant to gender differences in the relationship of BMI and cancer risk.

Adiponectin is the most abundant adipokine, secreted mainly from visceral adipose tissue and is inversely correlated with BMI. In terms of tumour development, this insulinsensitising agent is anti-inflammatory; anti-angiogenic; and inhibits tumour growth in animal models [29]. Beyond these mechanisms other candidate systems include obesity-related 
inflammatory cytokines, altered immune response, oxidative stresses, obesity-related hypoxia, adipocyte secreted proangiogenic factors, the nuclear factor $\kappa \beta$ system [20], and hypertension and lipid peroxidation for renal cancer [30], and acid-reflux for oesophageal adenocarcinoma. The mechanisms linking adiposity and less common malignancies are speculative.

Table 3. Candidate Mechanisms Linking Obesity and Cancer Risk

Biological mechanisms
Insulin and insulin-like growth factors (IGFs)
Sex steroids and sex-steroid binding globulin
Adipokines (e.g. adiponectin and leptin)
Obesity-associated hypoxia
Adipocyte secreted pro-angiogenic factors
Obesity-related inflammatory cytokines
Nuclear factor kB system
Altered immune response
Shared genetic susceptibility
Migrating adipose stromal cells
Mechanical mechanisms
Hypertension and renal cancer
Acid reflux and oesophageal adenocarcinoma
Inceased iodine uptake and thyroid cancer

In summary, there are several plausible biological explanations for linking adiposity with cancer risk - it is likely that not one "hat" fits all and indeed several mechanisms may be operating for some cancer types.

\section{Coherence}

\section{A Causal Conclusion should Not Fundamentally Contra- dict Present Substantive Knowledge}

Hill [4] use the term "generally known facts" to indicate that the knowledge against which an association is evaluated has to be undisputable. The difference in Hill's definitions of plausibility and coherence appears subtle - whereas plausibility is worded positively (an association that should be in line with substantive knowledge), coherence is verbalised negatively (an association that should not conflict with substantive knowledge). This can be exemplified in the apparent association of BMI and reduced risk of developing pre-menopausal breast cancer (as we saw above, an association restricted to Caucasian North American and European/Australian populations). Traditional explanation has been that greater body fatness may protect against premenopausal breast cancer through a greater number of anovulatory menstrual cycles [2]. However, this hypothesis fails to be coherent as body fatness expressed as waist circumference or waist-hip ratio (as a surrogate of central adiposity) is associated with an increased risk of premenopausal breast cancer [31]. A more coherent explanation (i.e. one that does not contradict a substantive theory) is that BMI is an inappropriate approximation of body adiposity in younger women. Importantly, adult attained height is a consistent predictor for pre-menopausal breast cancer [32] for this breast cancer subtype (i.e. pre-menopausal), "height" may disproportionately influences the BMI formula. For example, a short young woman may have a disproportionately high BMI, which appears protective.

\section{Experiment}

\section{Causation is more Likely if Evidence is Based on Randomised Experiments}

While there are many observational studies of the association of BMI and/or weight gain and cancer risk, there are only a small number examining the issues of reversibility of effect - in other words, is intentional weight loss in overweight and/or obese populations associated with reduced cancer risk? There are a plethora of studies in animals demonstrating that weight loss/calorie restriction is protective against tumour development and progression [33, 34]. However, in humans, there are no randomized data on this issue; data in the main comes from secondary analyses of large observational cohort studies. Most studies have been pertinent to risk reduction of breast cancer [35-41], with smaller numbers of studies on risk reduction of endometrial [42] and prostate cancers [43]. The emphasis on studies in breast cancer, however, serves to demonstrate that the question of reversibility is not trivial. First, for most (westernised) female populations, there is a steady increase in mean weight after the $20^{\text {th }}$ birthday through into the postmenopausal women [44]. In other words, the "baseline" mean weight is a "moving target", and what may be considered a weight reduction to a normal BMI category in one age group, may be maintenance of normal weight in another. Second, all studies to-date (even if they are cohort in design) have relied on recall methods to determine weights in younger adult age groups; such approaches may be subject to bias. Third, within these cohorts, there are three broad questions: (i) is weight loss in later reproductive years associated with reduced risk of post-menopausal breast cancer risk; (ii) is weight loss in early adult years associated with reduced risk of post-menopausal breast cancer; and (iii) is weight loss in early adult years associated with reduced risk of pre-menopausal breast cancer risk - and not all three are addressed in all papers. Accepting these limitations and difference in study design, the following observations can be stated for breast cancer: (i) weight loss in later reproductive years is associated with reduced risk of post-menopausal breast cancer risk in some [36, 40] but not all studies [37-39, 41]; (ii) weight loss in early reproductive years appears to reduce risk of post-menopausal breast cancer in most studies $[35,37,38,41]$; and (iii) whether or not weight loss in early reproductive years is associated with reduced risk of premenopausal breast cancer risk is equivocal as the data are sparse [39].

By contrast with population-based cohort studies (where weight reductions are generally modest and may not be sustained), post-bariatric surgery patients (morbidly obese: BMI $\geq 40 \mathrm{~kg} / \mathrm{m}^{2}$ ) experience significant and sustained 
weight loss (typically $20 \mathrm{~kg}$ ) and offer a unique population to explore the effects of long-term voluntary weight loss on cancer. Data, recently been published from the Swedish Obesity Study [45], a prospective controlled interventional trial and with greater than 10 years median follow-up, show that bariatric surgery is associated with a reduced risk of developing cancers. Similar findings are also seen in three retrospective North American cohorts [46-48]. Interestingly, the beneficial effects of bariatric surgery on cancer incidence reduction appear to be limited to women [49].

\section{Analogy}

\section{For Analogous Exposures and Outcomes An Effect has already been Shown}

Hill [4] wrote that it would be sometimes acceptable to "judge by analogy". Susser [50] interpreted Hill as claiming that "when one class of causal agents is known to have produced an effect, the standards for evidence that another agent of that class produces a similar effect can be reduced". At one level, it is difficult to apply "obesity" to a class of agent - however, at another level obesity may be considered to represent an altered physiological state typically characterised by an excess hormonal environment. In this setting, there are analogies in the human literature where excessive physiological exposures of hormones are associated with cancer risk: acromegaly (a chronic endocrine disorder characterised by sustained hypersecretion of growth hormone) is associated with increased risk of colorectal and thyroid cancers [51]; and hormonal replacement therapy is associated with increased risk of breast cancer in a timedependent manner [52].

An alternative view of analogy is: are there others settings where there is evidence that the risk exposure of interest is causally implicated in other diseases. Thus, for obesity, there is strong evidence through interventions such as bariatric surgery that obesity is implicated in the causation of cardiovascular disease and type 2 diabetes [53].

\section{OTHER STUDY ATTRIBUTES AND CAUSAL ASSOCIATION}

\section{Appropriate Adjustment for Available Confounding Factors}

Many of the original studies included in our systematic review [3] were not primarily designed with cancer occurrence as the primary endpoint. Thus, while many studies measured potential confounding factors relevant to the primary disease of interest, these factors may not have been relevant to the specific cancer being reported. We therefore listed each factor adjusted per study and classified these as whether or not it was relevant to the predisposition of that cancer i.e. cancer site-specific risk factor (CSS-RF), modified from the lists of risk factors tabulated in the IARC World Cancer Report [54]. For each site, the median number of CSS-RFs was calculated, and a categorical variable generated indicating above and below this median. When this dichotomized variable was entered into models of association for men and women, it was not significant, supporting the notion that appropriate adjustment for available confounding factors did not influence our findings.

\section{Measurement Error and Study Design}

Our meta-analysis [3] showed that the method of BMI determination (self-reported versus direct measurement of height and weight) influenced estimates of the BMI-cancer risk association in women, but not in men. Studies using self-reported determination of height and weight to calculate BMI tended to overestimate associations between BMI and cancer risk (at least in women) by an average of 0.10 of a relative risk. This is not surprising as self-reported of weight is known to underestimate true body weight; in turn, misclassification varies with age (increases in older individuals) and relative BMI (increases with increasing BMI) [55].

\section{Assessment of Residual Confounding}

It is almost impossible to totally exclude residual confounding in observational studies. However, our review [3] served to show that it is possible to demonstrate confounding that precludes the correct interpretation and further analysis of a risk factor exposure association. In the example of lung cancer, higher BMI appeared to be negatively associated with the risk of lung cancer - an observation that could be incorrectly interpreted that being obese protects against lung cancer. Analysis published in the supplemental files of our meta-analysis [3] showed: (i) the apparent "protective" association between BMI and lung cancer was largest the greater the proportion of ever-smokers for a given study; and (ii) analysis of studies where associations were stratified by smokers and non-smokers, it became apparent that the inverse association between BMI and lung cancer was limited to smokers. This is perhaps not too surprising as smokers have lower BMIs compared with age and sex-matched non-smokers [56], and of course, smoking is a major risk factor for lung cancer.

Sensitivity analyses can be undertaken to give an indication of the probable effect for included confounders, and of the probable effect of measurement error for included confounders, and of unmeasured confounders [57]. For unmeasured confounders, various plausible values for the strength of associations between the unmeasured confounder and outcome can be used and a series of fully adjusted exposure-outcome associations can be estimated. If these estimated associations are only moderately attenuated, unmeasured confounders are unlikely to be a major issue. In the sensitivity analysis of our review [3], we compared summary estimates per cancer site using minimally-adjusted versus maximally-adjusted risk estimates from studies. We found that there was little difference, supporting the notion that there was little residual confounding in our observations of the associations between BMI and sex-specific cancer risk.

\section{Lack of Alternative Explanations}

Conceivably, the associations of BMI and cancer risk might be explained through "bystander effects". Thus, for example, it is well recognised that BMI increases with increasing age, and in-turn, risk of many adult cancers increase with age [44] - raising the question: is increased BMI simply a function of age and not a causative risk factor for cancer. We addressed this in our systematic review [3] 


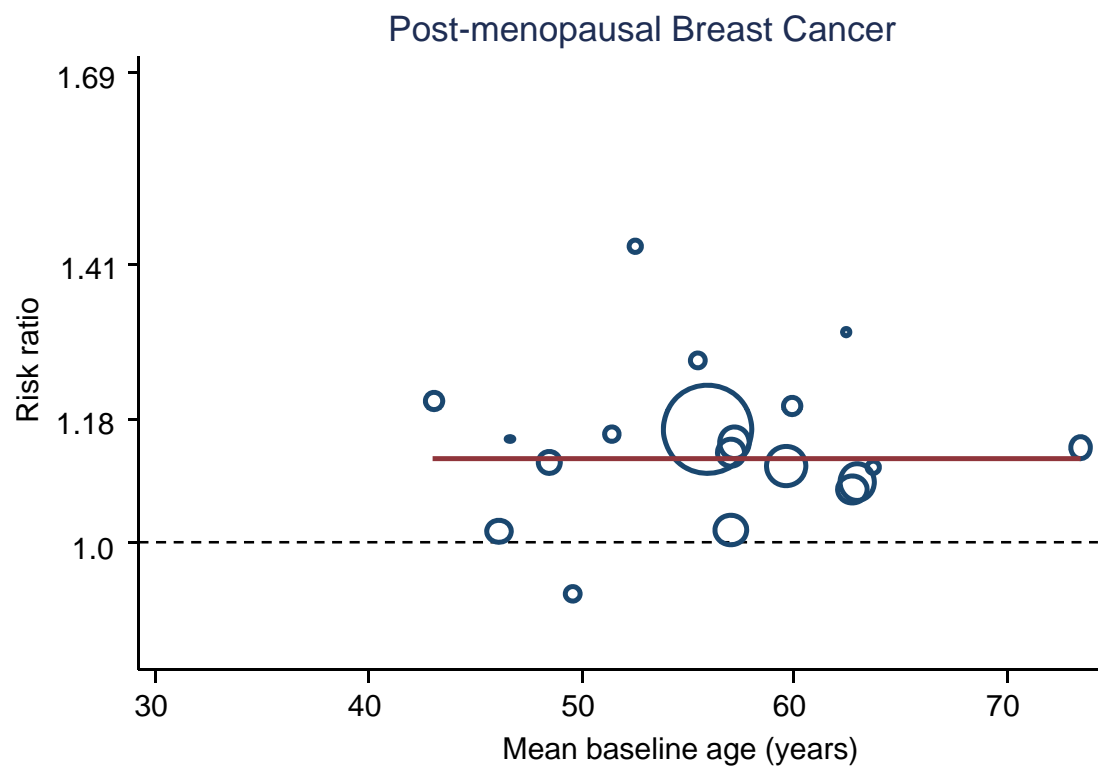

Fig. (4). Relationship of baseline mean age per study and risk of post-menopausal breast cancer. The size of each circle is proportional to the sample size of the cohort.

through examining plots of baseline mean ages in studies with subsequent risk - there appears to be no relationship. This is illustrated for post-menopausal breast cancer in Fig. (4).

A similar type of question may be: individuals who eat energy-dense food, such as fats, develop obesity; is it not the fatty foods rather than the state of adiposity per se which is relevant? Dietary fat content has been studied for almost four decades in relation to risk of breast and colorectal cancers, but extensive reviews of these data yield no definitive (but lots of inconsistent) evidence of association [2].

Finally, like any review of the literature, there is the risk of publication bias. In our systematic review [3], there was evidence for funnel plot asymmetry for colon cancer in men and women, with smaller studies showing larger effects of BMI ( $p=0.002$ and 0.006 , respectively) but little evidence for the other cancer types. We tested the potential effect of small studies on these estimates by repeating the analyses for colon cancer associations excluding studies less than 150 cases - there was no influence on summary estimates, suggesting that publication patterns were unlikely to be a major source of bias.

\section{CONCLUSION}

In an ideal world, prospective trans-generational observational studies would establish accurate measures of exposure, through repeated measurements of that exposure, from early life until the event of interest and/or death [58]. Of course, no such study exists to address the exposure of excess body weight and cancer risk. Thus, it is only possible to infer through indirect data the answer to questions like: is childhood obesity per se pertinent to the development of adult cancers; when in the life-course pathway, is weight gain relevant, and is this different for men and women, and across different sites. As we develop cohorts that approach life-course models (rather than the current snap-shot approach), we will have to in parallel develop statistical approaches to best characterise and quantify the cumulative effect of the exposure of excess body weight.

In this review, we tested available data on the association of BMI and cancer risk (collected through a large multicancer type systematic review) against the Bradford-Hill criteria of causal association. The findings argue that the data support strength of association, consistency, specificity, temporality, biological gradient, plausibility, coherence and probably analogy. However, the experimental evidence supporting reversibility is currently lacking, though indirect evidence from longitudinal data in cohort studies and longterm follow-up post-bariatric surgery is emerging. We additionally assessed these data against appropriate adjustment for available confounding factors; measurement error and study design; and residual confounding, and found lack of alternative explanations.

It is not suggested that any of these criteria in itself is necessary or sufficient for causality to be declared, but each strengthens the evidence in its favour. Accordingly, we conclude that there is considerable evidence to support a causal association between BMI and risk for many cancer types, but in order to establish the role of weight control in cancer prevention, there is a need to develop trial frameworks in which to better test reversibility.

\section{ACKNOWLEDGEMENTS}

This study was partly funded by an award to AGR from the British Medical Association.

\section{REFERENCES}

[1] IARC. International Agency for Research in Cancer. Weight control and physical activity. In: Vainio H, Bianchini F, Eds. Lyon: IARC Press 2002.

[2] WCRF. World Cancer Reserach Fund. Food, Nutrition, Physical Activity, and the Prevention of Cancer: a Global Perspective. $2^{\text {nd }}$ ed. Washington: American Institute for Cancer Research 2007. 
[3] Renehan A, Tyson M, Egger M, Heller RF, Zwahlen M. Body mass index and incidence of cancer: a systematic review and metaanalysis of prospective observational studies. Lancet 2008; 371(9612): 569-78.

[4] Hill AB. The environment and disease: association or causation? Proc R Soc Med Lond 965; 88: 295-300.

[5] Hofler M. The Bradford Hill considerations on causality: a counterfactual perspective. Emerg Themes Epidemiol 2005; 2: 11.

[6] Lawlor DA, Davey Smith G, Bruckdorfer KR, Kundu D, Ebrahim S. Those confounding vitamins: what can we learn from the differences between observational versus randomised trial evidence? Lancet 2004; 363: 1724-7.

[7] WHO. world health organization. obesity: preventing and managing the global epidemic. In: Technical Report Series no. 894, 2000. Available from: http: //whqlibdoc.who.int/trs/WHO_TRS 894.pdf

[8] World Health Organisation expert consultation. Appropriate bodymass index for Asian populations and its implications for policy and intervention strategies. Lancet 2004; 363(9403): 157-63.

[9] Samanic C, Gridley G, Chow WH, Lubin J, Hoover RN, Fraumeni JF, Jr. Obesity and cancer risk among white and black United States veterans. Cancer Causes Control 2004; 15(1): 35-43.

[10] Palmer JR, Adams-Campbell LL, Boggs DA, Wise LA, Rosenberg L. A prospective study of body size and breast cancer in black women. Cancer Epidemiol Biomarkers Prev 2007; 16(9): 1795802 .

[11] Higgins JP, Thompson SG. Quantifying heterogeneity in a metaanalysis. Stat Med 2002; 21(11): 1539-58.

[12] Romero-Corral A, Montori VM, Somers VK, et al. Association of bodyweight with total mortality and with cardiovascular events in coronary artery disease: a systematic review of cohort studies. Lancet 2006; 368(9536): 666-78.

[13] Bogers RP, Bemelmans WJ, Hoogenveen RT, et al. Association of overweight with increased risk of coronary heart disease partly independent of blood pressure and cholesterol levels: a metaanalysis of 21 cohort studies including more than 300000 persons. Arch Intern Med 2007; 167(16): 1720-8.

[14] Vazquez G, Duval S, Jacobs DR, Jr, Silventoinen K. Comparison of body mass index, waist circumference, and waist/hip ratio in predicting incident diabetes: a meta-analysis. Epidemiol Rev 2007; 29: $115-28$.

[15] Pischon T, Boeing H, Hoffmann K, et al. General and abdominal adiposity and risk of death in Europe. N Engl J Med 2008; 359(20): 2105-20

[16] Flegal KM, Graubard BI, Williamson DF, Gail MH. Excess deaths associated with underweight, overweight, and obesity. JAMA 2005; 293(15): 1861-7.

[17] Prospective Studies Collaboration. Body-mass index and causespecific mortality in 900000 adults: collaborative analyses of 57 prospective studies. Lancet 2009; 373(9669): 1083-96.

[18] Orsini N, Bellocco R, Greenland S. Generalized least squares for trend estimation of summarized dose-response data. Stata J 2006; 6(1): 40-57.

[19] Renehan AG, Roberts DL, Dive C. Obesity and cancer: pathophysiological and biological mechanisms. Arch Physiol Biochem 2008; 114(1): 71-83.

[20] Renehan AG, Frystyk J, Flyvbjerg A. Obesity and cancer risk: the role of the insulin-IGF axis. Trends Endocrinol Metab 2006; 17(8): 328-36.

[21] Renehan AG, Zwahlen M, Minder C, O'Dwyer ST, Shalet SM, Egger M. Insulin-like growth factor (IGF)-I, IGF binding protein-3, and cancer risk: systematic review and meta-regression analysis. Lancet 2004; 363: 1346-53.

[22] Rinaldi S, Peeters PH, Berrino F, et al. IGF-I, IGFBP-3 and breast cancer risk in women: The European Prospective Investigation into Cancer and Nutrition (EPIC). Endocr Relat Cancer 2006; 13(2): 593-605.

[23] Baglietto L, English DR, Hopper JL, Morris HA, Tilley WD, Giles GG. Circulating insulin-like growth factor-I and binding protein-3 and the risk of breast cancer. Cancer Epidemiol Biomarkers Prev 2007; 16(4): 763-8

[24] Juul A, Bang P, Hertel NT, et al. Serum insulin-like growth factor-I in 1030 healthy children, adolescents, and adults: relation to age, sex, stage of puberty, testicular size, and body mass index. J Clin Endocrinol Metab 1994; 78(3): 744-52.
[25] Harvie M, Renehan AG, Frystyk J, et al. Paradoxical increases in serum total IGF-I and maintenance of free IGF-I levels following 12 months of intentional weight loss in pre-menopausal women at increased risk of breast cancer [submitted to this Special Issue]. BMC Open J Obes 2009.

[26] Calle EE, Kaaks R. Overweight, obesity and cancer: epidemiological evidence and proposed mechanisms. Nat Rev Cancer 2004; 4(8): 579-91.

[27] Derby CA, Zilber S, Brambilla D, Morales KH, McKinlay JB. Body mass index, waist circumference and waist to hip ratio and change in sex steroid hormones: the massachusetts male ageing study. Clin Endocrinol (Oxf) 2006; 65(1): 125-31.

[28] Key TJ, Appleby PN, Reeves GK, et al. Body mass index, serum sex hormones, and breast cancer risk in postmenopausal women. J Natl Cancer Inst 2003; 95(16): 1218-26.

[29] Rose DP, Komninou D, Stephenson GD. Obesity, adipocytokines, and insulin resistance in breast cancer. Obes Rev 2004; 5(3): 15365.

[30] Gago-Dominguez M, Castelao JE, Yuan JM, Ross RK, Yu MC. Lipid peroxidation: a novel and unifying concept of the etiology of renal cell carcinoma (United States). Cancer Causes Control 2002; 13(3): 287-93.

[31] Harvie M, Hooper L, Howell AH. Central obesity and breast cancer risk: a systematic review. Obes Rev 2003; 4(3): 157-73.

[32] Gunnell D, Okasha M, Smith GD, Oliver SE, Sandhu J, Holly JM. Height, leg length, and cancer risk: a systematic review. Epidemiol Rev 2001; 23(2): 313-42.

[33] Dirx MJ, Zeegers MP, Dagnelie PC, van den Bogaard T, van den Brandt PA. Energy restriction and the risk of spontaneous mammary tumors in mice: a meta-analysis. Int $\mathrm{J}$ Cancer 2003; 106(5): 766-70.

[34] Hursting SD, Lavigne JA, Berrigan D, Perkins SN, Barrett JC Calorie restriction, aging, and cancer prevention: mechanisms of action and applicability to humans. Ann Rev Med 2003; 54: 13152 .

[35] van den Brandt PA, Dirx MJ, Ronckers CM, van den Hoogen P, Goldbohm RA. Height, weight weight change, and postmenopausal breast cancer risk: The Netherlands Cohort Study. Cancer Causes Control 1997; 8(1): 39-47.

[36] Parker ED, Folsom AR. Intentional weight loss and incidence of obesity-related cancers: the Iowa Women's Health Study. Int J Obes Relat Metab Disord 2003; 27(12): 1447-52.

[37] Harvie M, Howell A, Vierkant RA, et al. Association of gain and loss of weight before and after menopause with risk of postmenopausal breast cancer in the Iowa women's health study. Cancer Epidemiol Biomarkers Prev 2005; 14(3): 656-61.

[38] Eng SM, Gammon MD, Terry MB, et al. Body size changes in relation to postmenopausal breast cancer among women on Long Island, New York. Am J Epidemiol 2005; 162(3): 229-37.

[39] Lahmann PH, Schulz M, Hoffmann K, et al. Long-term weight change and breast cancer risk: the European prospective investigation into cancer and nutrition (EPIC). Br J Cancer 2005; 93(5): 582-9.

[40] Eliassen AH, Colditz GA, Rosner B, Willett WC, Hankinson SE. Adult weight change and risk of postmenopausal breast cancer. JAMA 2006; 296(2): 193-201.

[41] Ahn J, Schatzkin A, Lacey JV, et al. Adiposity, adult weight change, and postmenopausal breast cancer risk. Arch Intern Med 2007; 167(19): 2091-102.

[42] Trentham-Dietz A, Nichols HB, Hampton JM, Newcomb PA. Weight change and risk of endometrial cancer. Int $\mathrm{J}$ Epidemiol 2006; 35(1): 151-8.

[43] Rodriguez C, Freedland SJ, Deka A, et al. Body mass index, weight change, and risk of prostate cancer in the Cancer Prevention Study II Nutrition Cohort. Cancer Epidemiol Biomarkers Prev 2007; 16(1): 63-9.

[44] Zaninotto P, Head J, Stamatakis E, Wardle H, Mindell J. Trends in obesity among adults in England from 1993 to 2004 by age and social class and projections of prevalence to 2012. J Epidemiol Commun Health 2009; 63(2): 140-6.

[45] Sjostrom L, Gunmmessson A, Sjostrom CD, et al. Effects of bariatric surgery on cancer incidences in Swedish Obese Subjects, SOS, a prospective controlled intervention trial. Lancet Oncol 2009; 10(7): 653-62 
[46] Christou NV, Lieberman M, Sampalis F, Sampalis JS. Bariatric surgery reduces cancer risk in morbidly obese patients. Surg Obes Relat Dis 2008; 4(6): 691-5.

[47] Adams TD, Stroup AM, Gress RE, et al. Cancer incidence and mortality after gastric bypass surgery. Obesity (Silver Spring) 2009; 17(4): 796-802.

48] McCawley GM, Ferriss JS, Geffel D, Northup CJ, Modesitt SC. Cancer in obese women: potential protective impact of bariatric surgery. J Am Coll Surg 2009; 208(6): 1093-8.

[49] Renehan AG. Bariatric surgery, weight reduction and cancer prevention. Lancet Oncol 2009; 10: 640-1.

[50] Susser M. What is a cause and how do we know one? A grammar for pragmatic epidemiology. Am J Epidemiol 1991; 133(7): 63548.

[51] Renehan AG, Brennan BM. Acromegaly, growth hormone and cancer risk. Best Pract Res Clin Endocrinol Metab 2008; 22(4): $639-57$. Beral V. Breast cancer and hormone-replacement ther

Sjostrom L, Lindroos AK, Peltonen M, et al. Lifestyle, diabetes, and cardiovascular risk factors 10 years after bariatric surgery. N Engl J Med 2004; 351(26): 2683-93.

[54] Stewart BW, Kleihues P. World Cancer Report. Lyon: IARC 2003.

[55] Kuczmarski MF, Kuczmarski RJ, Najjar M. Effects of age on validity of self-reported height, weight, and body mass index: findings from the Third National Health and Nutrition Examination Survey, 1988-1994. J Am Diet Assoc 2001; 101(1): 28-34.

[56] Canoy D, Wareham N, Luben R, et al. Cigarette smoking and fat distribution in 21,828 British men and women: a population-based study. Obes Res 2005; 13(8): 1466-75.

[57] Greenland S. Basic methods for sensitivity analysis of biases. Int J Epidemiol 1996; 25: 1107-16.

[58] Ben-Shlomo Y, Kuh D. A life course approach to chronic disease epidemiology: conceptual models, empirical challenges and interdisciplinary perspectives. Int J Epidemiol 2002; 31(2): 285-93.

Received: April 22, 2009

Revised: June 16, 2009

Accepted: June 16, 2009

(C) Renehan et al.; Licensee Bentham Open.

This is an open access article licensed under the terms of the Creative Commons Attribution Non-Commercial License (http: //creativecommons.org/licenses/by$\mathrm{nc} / 3.0 /$ ), which permits unrestricted, non-commercial use, distribution and reproduction in any medium, provided the work is properly cited. 